\title{
F2006M161
}

\section{CABLE HARNESS DESIGN AND ASSEMBLY PLANNING USING IMMERSIVE VIRTUAL REALITY}

\author{
${ }^{1}$ Ritchie, James ${ }^{*},{ }^{1}$ Robinson, Graham, ${ }^{1}$ Day, Phillip, ${ }^{2}$ Dewar, Richard, ${ }^{1}$ Simmons, John ${ }^{1}$ Sung, \\ Raymond \\ ${ }^{1}$ The Scottish Manufacturing Institute, Heriot-Watt University, Edinburgh, UK
}

KEYWORDS - Cable harness, design, assembly planning, virtual reality, virtual engineering.

ABSTRACT - In this paper, the use of head mounted display immersive virtual reality (VR) is investigated as both a cable harness design routing and an assembly planning tool. Due to the nature of this technology being more intuitive as an interface for generating design and process planning information, it is important to understand in detail the activities being carried out by the designer whilst immersed in the 3D virtual environment since health and safety recommendations dictate a maximum of around 20 minutes exposure for the user.

After covering earlier work comparing CAD/VR productivity studies, follow-on work is outlined describing an immersive VR-based design platform developed for the design, assembly planning and installation planning of cable harnesses. This is presented in the form of recent, extensive system evaluations which analysed a number of participants carrying out cable routing design tasks. User activities were broken down using a novel design task categorisation scheme which enabled a detailed understanding of the design activity being carried out. This successfully illustrated where the designers were spending their valuable time being creative, generating design information, navigating through the model, correcting errors, accessing help information, etc. and, for the first time, allowed the system to be statistically evaluated in terms of performance and category relationships. The categorisation scheme provides a valuable formal tool for understanding design behaviour and could be used not only with immersive VR design systems but for comparing different design platforms such as CAD systems. As well as this, non-intrusive logging also enable assembly planner activities to be monitored and recorded; the subsequent analysis of this data enabled chronological cable harness assembly and cable harness installation plans to be automatically produced along with the incorporation of real-world estimates of assembly times.

TECHNICAL PAPER - The use of interactive immersive virtual reality (VR) will become popular in the near future for the conceptual and detail design of new products, particularly within the car industry. The use of VR will probably mirror the use of CAD systems within this sector in the 1970s which became generally available for 2D drafting on on low-cost PCbased platforms and evolved into CAD systems with extensive real-time solid modelling capabilities. Also important is the generation of downstream information in the form of manufacturing and assembly plans. Since VR will be an significant competitive technology in industry it is important that its impact and application are understood so that interfaces and systems can be developed which substantially enhance the capabilities of both design and manufacturing engineers. This work focuses on head-mounted display (HMD) immersive VR being used as a tool for the design of cable harness routes and the subsequent automatic generation of harness assembly plans and installation plans. The main focus being on proving whether the engineers design activities can be analysed and categorised such that the design process can be understood and improvements to the system and associated interfaces can be highlighted to better improve designer performance. 
IMMERSIVE VIRTUAL REALITY - There are many areas of research in which immersive VR has been used for mechanically engineered products (1). For this research, HMD technology was chosen because the user the user is surrounded by a virtual world generated by computer graphics and the models within this can be interacted with in real time (Figure 1) depending on the input devices and tracking devices attached to the system. The helmet incorporates sensors to track the user's physical movements as well as allowing for relative sound input.

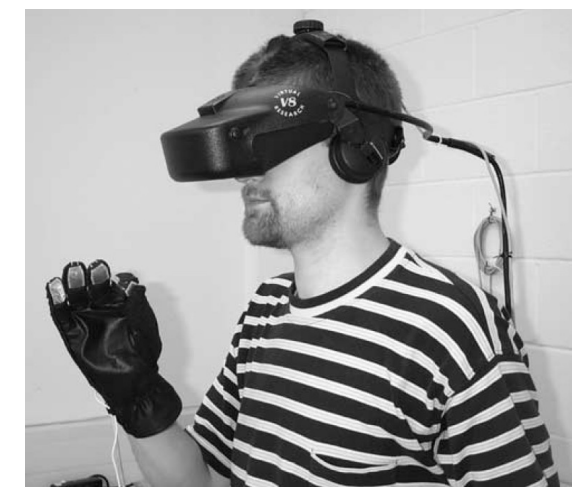

Figure 1: Head-Mounted Display (HMD)

If HMDs are to be used within the design platforms of the future research must be carried out to determine how this can best be used in design and assembly planning domains since the recommended standard length of exposure is around 20 minutes (2-6).

In the area of product design, VR systems are impacting on how engineers develop products and work together to generate ideas and produce the information necessary for cost-effective manufacture (1). Gomes de Sa and Zachmann (7) see a role for immersive VR throughout the whole product development cycle but it needs to be as easy to use as CAD. Fortunately, it tends to be easier to use than $\mathrm{CAD}$, as discovered by $\mathrm{Ng}$ et al. where the training times for using an immersive VR design system were much shorter (8). Cruz-Niera et al (9) used a C2 $\mathrm{CAVE}^{\mathrm{TM}}$ environment for architectural design so that students could appreciate a model at full scale and Weyrich and Drews (10) used a virtual workbench to design and found that the method appears to effectively support how engineers think during the design process. The capability of VR in conceptual design was demonstrated by COVIRDS (COnceptual VIRtual Design System) which showed the potential interactive capabilities of immersive virtual design (11) using hand tracking and voice input for a VR-based CAD environment. Varga et al (12) investigated the use of hand motion as a means of creating conceptualised geometry and, in another study whilst $\mathrm{Ng}$ compared an immersive VR design environment called CHIVE (Cable Harnessing in Virtual Environments) with a number of CAD systems and demonstrated that HMD virtual technology gives considerable productivity benefits over the CAD (13).

Cable harness design, the chosen focus of this work, is a major, tail-end design activity and, even with extensive CAD-based packages available for this task, companies still employ physical prototypes to check cable paths (8). Early cable harness design work attempted to automate the choice of a cable harness route (14), with subsequent work using genetic algorithms to tackle the same problem (15). Wolter and Krol routed 'strings' around 'solid' parts (16) and robot path planning has also been applied for pipe routing (17). Recent work at Heriot-Watt University $(8,18)$ showed that immersive VR gives advantages in this design process. Iowa State University (19) used a VR system for routing flexible hoses and validated 
VR as a practical tool. Work at Boeing (20) in the area of augmented reality indicated the early advantages of virtual technologies in assembling cable harnesses. A survey of the industrial companies showed that there was a need for human expert intervention to make fine adjustments and verify solutions (8); therefore it is timely to investigate the nature of new human-driven tools to support interaction with data in this domain. The key issue is the integration of the human-in-the-loop by treating the operator as integral to system (21). This emphasises the need to examine creative design activities in more detail to see how better tools and methods can be introduced to support the cable design task and VR's unique capability to immerse the user in a design experience makes it an ideal domain in which to carry out detailed design studies of this kind and to examine its potential in assembly planning. In this work an advanced immersive VR-based cable harness design system based on the table-top metaphor (22) and using comprehensive user logging was therefore developed to non-intrusively collect detailed information relating to the design solutions and approaches used by a number of engineers as well as automatically generating assembly plans from user interactions.

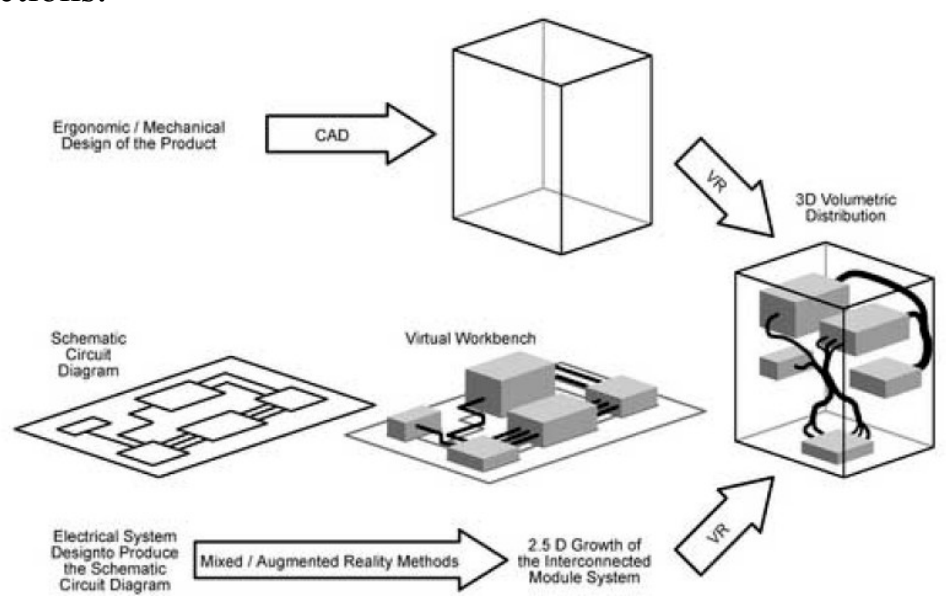

Figure 2: Workbench metaphor

\section{APPARATUS AND METHODOLOGY}

APPARATUS: COSTAR EXPERIMENTAL PLATFORM --The system developed for this research was called COSTAR (Cable Organisation Systems Through Alternative Reality) and was implemented on an SGI ${ }^{\circledR}$ Octane $2^{\mathrm{TM}}$ with V12 dual head graphics driving each eye on a V8 stereo HMD. Peripherals included a Flock of Birds ${ }^{\circledR}$ magnetic tracking system for position monitoring and Pinch ${ }^{\circledR}$ Gloves. The software platform used SENSE8 ${ }^{\circledR}$ WorldToolKit ${ }^{\circledR}$ release 9 . The COSTAR system enables the engineer to design and plan cable harness assemblies within the immersive VR environment, with all design functions including the creation of new objects being performed by creating points in 3D space and joining them to form segmented cable harness routes (Figure 3). Interactions are achieved by means of a custom-built ring menu system $(23,24)$ and pinch gestures.

Subsequent editing of the cables is possible by selecting the plotted points and bending them around obstructions, bunching or pulling them together to form cable harness bundles, inserting additional points and adding connectors and fasteners; figure 4 shows the system with various operations being performed. As these are being carried out COSTAR logs chronologically, all user activities, motions and object interfacing/creation. 


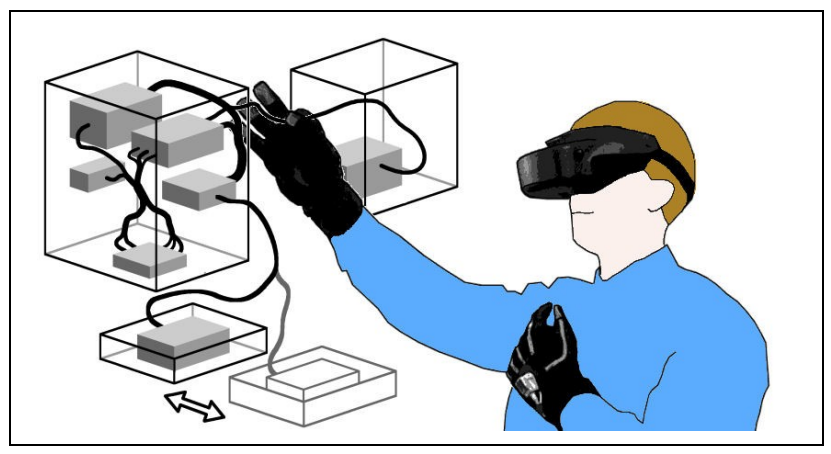

Figure 3: The COSTAR cable harness design system
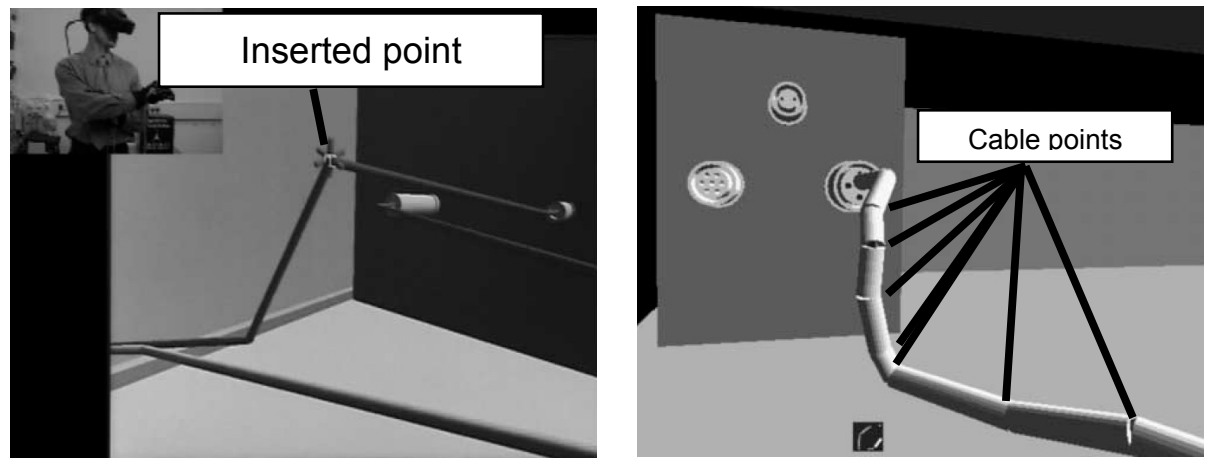

Figure 4: Creating cable route geometry

EXPERIMENTAL METHODOLOGY FOR CABLE HARNESS DESIGN TASK

ANALYSIS - The experimental cable harness design tasks were intended to be completed in around 20 minutes. Three loosely constrained creative design tasks were organised to evaluate the utilisation of each designer's time. These covered the major common design activities for the industrial contributors to this work, such as routing, bundling, cable modification, choosing connectors, etc. and involved consecutive stages of the overall cable harness design process; namely (1) outline design; (2) detailed design; and (3) redesign. Tasks 1 and 2 were used mainly for training and familiarisation and task 3 for design task analysis. The log files from these activities were subsequently decomposed and analysed in order to ascertain which aspects of the virtual cable harness design system were used, the kinds of activity the designers performed and their distribution throughout the total design time taken. All of the tasks were carried out within the same 'product' model (Figure 5) and were as follows:

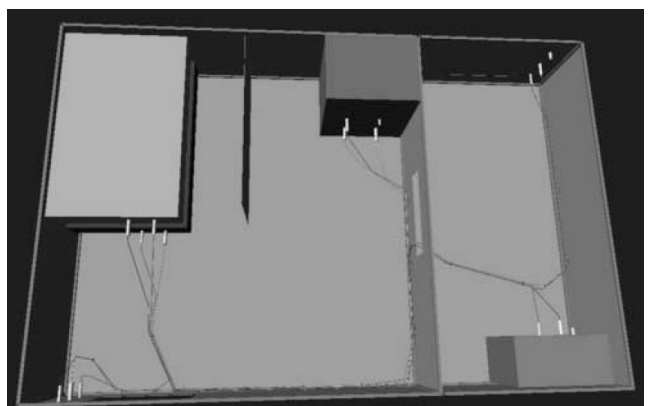

Figure 5: Model on completion of the experimental tasks

(1) Outline Design: to generate two new electrical interconnections within the product model with two specific connectors and a specific cable type. The goal was to define the electrical interconnections provided by the harness. 
(2) Detailed Design: contained pre-defined cable interconnections in a model, a number of which had already been routed through a sequence of cable clips to produce a harness design. Three additional cables that defined electrical interconnectivity but had not yet been and the user instructed to carry this out.

(3) Redesign: The final required them to effect 'engineering change requests' requiring redesign of the harness in some manner including the addition of a new cable and the removal of another and its associated connectors. Finally, there was another 'undefined' 'throughwall' error within the model that the participants were required to locate and fix.

Ten experienced CAD participants completed the experiments, all of whom were male, eight were 20 - 29 years of age and two were $30-39$ years of age, all with normal or corrected-tonormal vision. Everyone was right-hand dominant with eight being right eye and two being left-eye dominant. Identical session structures were used at each of the three evaluation task sessions. The immersive design activity was followed by a structured discussion session during which feedback about the system and the participant's experience with it was collected.

ANALYSIS OF RESULTS - The results collected via the log files included performance and usage data, system usability data and system functionality data along with informal subjective discussions regarding system performance and future changes. From the results for task 3 , the usage of the system was analysed by means of various novel categories of functionality and system state developed for this purpose. In relation to the working environment, it was decided to analyse the time spent in the model, in help and in the menus so that their influence on any design task could be compared against any proposed detailed activity task

categorisation. This resulted in the development of a set of environmental categories and, on analysing the log files, produced the distribution shown in Table 1 and Figure 6. This demonstrates the average percentage of time spent in each of the new environmental category subdivisions as the designers completed design task 3 and show that a very high percentage of the time (69\%) involved the users carrying out activities within the model and being creative, illustrating the intuitive and easy-to-operate nature of the virtual design tool. Only a small proportion of the time ( $8 \%$ ) was spent in 'help/task instruction' again supporting both the experimental evidence and the informal feedback from the users that the system was easy and intuitive to use.

\begin{tabular}{|c|c|c|c|c|c|}
\cline { 2 - 6 } \multicolumn{1}{c|}{} & \multicolumn{5}{c|}{ Environmental Categories } \\
\cline { 2 - 6 } & Model & $\begin{array}{c}\text { Help/Task } \\
\text { Instruction }\end{array}$ & $\begin{array}{c}\text { Menu } \\
\text { (No model } \\
\text { visible) }\end{array}$ & $\begin{array}{c}\text { Menu } \\
\text { (model } \\
\text { visible) }\end{array}$ & Total \\
\hline $\begin{array}{c}\text { Mean } \\
\text { Time (s) }\end{array}$ & 867 & 101 & 289 & 0 & 1257 \\
\hline$\%$ & $69 \%$ & $8 \%$ & $23 \%$ & $0 \%$ & $100 \%$ \\
\hline
\end{tabular}

Table 1: Environmental category subdivisions for design task 3 


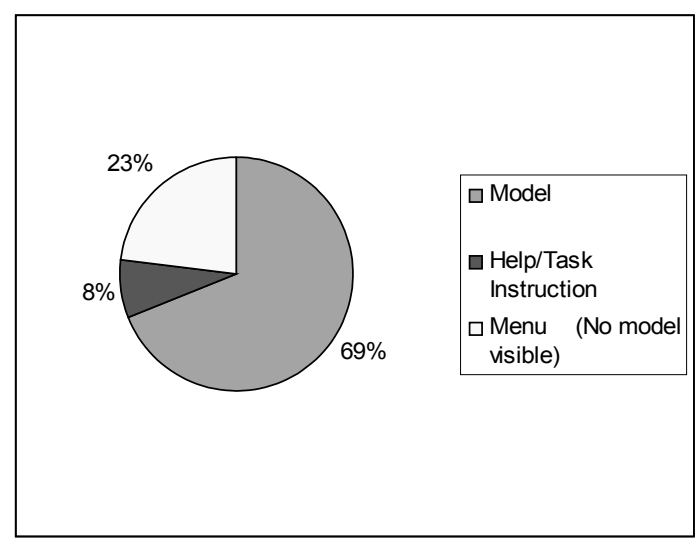

Figure 6: Average time distribution for environmental category subdivisions

After analysing the data and the associated design process activities, the various action sequences within the log files were grouped together to enable a numerical and statistical analysis of the cable harness design approach used by the participants. From these data, a set of design activity categories were defined so that participant activities could be compared (Table 1). The four action sequence or activity categories chosen were:

Design: all activity that the user carries out to directly amend the design solution or associated documentation.

Information: all user activity which involves them acquiring information from a text screen. System Operation: all activities which are required by the user to operate the system but does not affect the design solution.

Navigation: all activity which modifies the participant's viewpoint of the model but does not normally change the design solution itself.

Design was further subdivided into three subcategories, namely:

Design - Goal: user actions which alter the design solution/model and advance the design towards its final state.

Design - Support: activities which do not produce a change to the design solution but enable the user to subsequently alter the design.

Drag \& Drop (Position Edit): the movement of an object by the user interactively within the model environment.

The results from this categorisation structure are shown in Table 2 and Figure 7.

\begin{tabular}{|c|c|c|c|c|c|c|c|}
\hline & \multicolumn{6}{|c|}{ Activity Category } & \multirow[b]{2}{*}{ Totals } \\
\hline & $\begin{array}{l}\text { Desig } \\
\text { n Goal }\end{array}$ & $\begin{array}{c}\text { Design } \\
\text { Suppo } \\
\text { rt }\end{array}$ & $\begin{array}{c}\text { Drag\& } \\
\text { Drop }\end{array}$ & $\begin{array}{c}\text { Informatio } \\
n\end{array}$ & $\begin{array}{l}\text { System } \\
\text { Operation }\end{array}$ & Navigation & \\
\hline $\begin{array}{c}\text { Mean } \\
\text { Time (s) }\end{array}$ & 131 & 57 & 157 & 106 & 296 & 510 & 1257 \\
\hline St.Dev. & 52 & 13 & 130 & 36 & 77 & 160 & 326 \\
\hline$\%$ & $10 \%$ & $5 \%$ & $12 \%$ & $8 \%$ & $24 \%$ & $41 \%$ & $100 \%$ \\
\hline
\end{tabular}

Table 2 - Average Time for Detailed Design Categorisation 


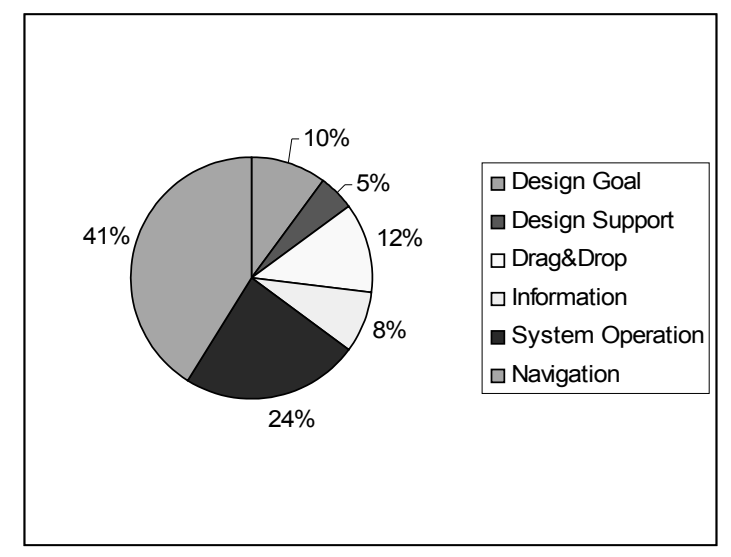

Figure 7 - Average Percentage Detailed Design Categorisation

From these data, a large proportion of the time was spent navigating (41\%). This is due to the experimental model being presented to the designer in super-scale; i.e. the model surrounded the engineer. Flying was employed as the navigation mode because it was the traditional type of navigation used with a HMD with the flying speed was kept constant in order to reduce confounding variables in experimentation. However, with such a large proportion of the time being spent moving around the model, the categorisation scheme shows that, during the creative design process, it would be advantageous to reduce navigation time considerably. Around $27 \%$ of the time within the system was spent on design-related tasks. Although a high percentage of the time it was apparent using this categorisation scheme that there were opportunities to improve the interface in terms of navigation and menu interfaces to free up even more time for creative design.

\section{CABLE HARNESS ASSEMBLY/CABLE HARNESS INSTALLATION PLANNING -} One of the major benefits of any computer aided design (CAD) system is the generation of downstream manufacturing information. This study investigated the possibility of automatically generating useable assembly plans in a VR system by allowing the manufacturing planner to explore the cable harness and associated connector geometries to evaluate a cable harness assembly process planning sequence and, secondly, to follow this up by 'installing' the cable harness in a virtual model to automatically generate an installation assembly plan. This follows up on the work carried out by Ritchie et al (25) which demonstrated that it was possible to produce production assembly plans via an immersive VR interface. To demonstrate how it is possible to cross refer to actual assembly data in a virtual environment application - tables of standards were applied in this work so that as the assembly plans are generated real-world standards values were allocated to virtual equivalent tasks enabling the development and generation of production-standard assembly plans.

Once the manufacturing engineer was immersed in the virtual environment they were then able to navigate around the cable harness itself and ergonomically and chronologically choose which connectors and cables to join together thus facilitating actual harness build. A similar approach was used when installing the cable harness into the actual assembly itself. The interface for assembly planning is shown in Figure 8 and the assembly plans for both the harness itself and its installation along with the corresponding real-world assembly times for each operation are shown and Figure 9. 


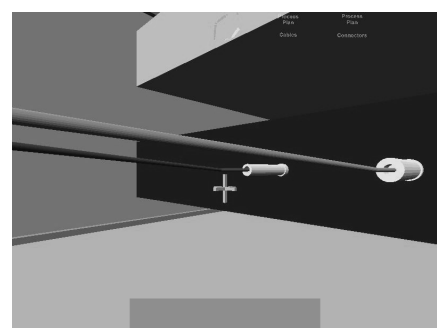

Select Cable

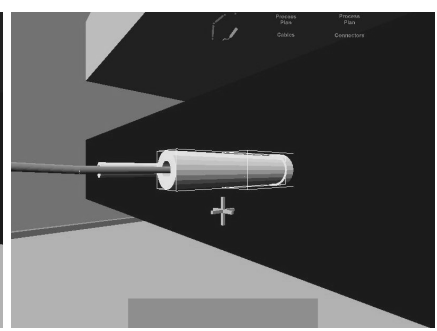

Select Bulkhead

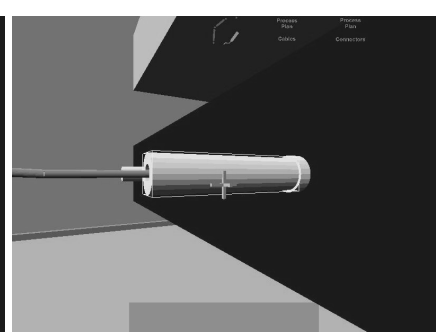

Select Connector

Figure 8: VR User Interface for Assembly Planning

CABLE HARNESS BUILDING SEQUENCE

\begin{tabular}{|c|l|l|c|c|}
\hline $\begin{array}{c}\text { Op } \\
\text { Num }\end{array}$ & W/Centre & \multicolumn{1}{|c|}{ Assembly Instructions } & Tooling & $\begin{array}{c}\text { Assembly } \\
\text { Time (s) }\end{array}$ \\
\hline 10 & Cable Bench & $\begin{array}{l}\text { Connect cable CAB02(Type: CONTROLCY Number of Cores: 7 } \\
\text { Core Cross-Section: 1 Colour (RGB): 225,125,0) to inline connector } \\
\text { CON23 (Type: plug Shell size: 2 Number of poles 7) }\end{array}$ & $\begin{array}{c}\text { Hand } \\
\text { Assembly }\end{array}$ & 10.3 \\
\hline 20 & Cable Bench & $\begin{array}{l}\text { and inline connector CON24 (Type: socket Shell size: 2 Number of } \\
\text { poles 7) }\end{array}$ & $\begin{array}{c}\text { Hand } \\
\text { Assembly }\end{array}$ & 27.18 \\
\hline 30 & Cable Bench & $\begin{array}{l}\text { Connect cable CAB01(Type: SINGLECORE Number of Cores: 1 } \\
\text { Core Cross-Section: 4.8 Colour (RGB): 255,0,0) to inline connector } \\
\text { CON22 (Type: plug Shell size: 1 Number of poles 2) }\end{array}$ & $\begin{array}{c}\text { Hand } \\
\text { Assembly }\end{array}$ & 15.70 \\
\hline 40 & Cable Bench & $\begin{array}{l}\text { and inline connector CON21 (Type: socket Shell size: 1 Number of } \\
\text { poles 2) }\end{array}$ & $\begin{array}{c}\text { Hand } \\
\text { Assembly }\end{array}$ & 14.24 \\
\hline
\end{tabular}

INSTALL CABLE HARNESS ASSEMBLY INTO EQUIPMENT

\begin{tabular}{|c|c|l|c|c|}
\hline $\begin{array}{c}\text { Op } \\
\text { Num }\end{array}$ & W/Centre & \multicolumn{1}{c|}{ Assembly Instruction } & Tooling & $\begin{array}{c}\text { Assembly } \\
\text { Time (s) }\end{array}$ \\
\hline 10 & Assy Station & $\begin{array}{l}\text { Connect inline connector CON21 (Type: socket Shell size: } 1 \\
\text { Number of poles 2) to bulkhead connector CON01 (Type: plug } \\
\text { Shell size: 1 Number of poles 2) located at position (3250,- } \\
500,3725) \text { and Orientation (0,-0,0.707107,0.707107) }\end{array}$ & $\begin{array}{c}\text { Hand } \\
\text { Assembly }\end{array}$ & 7.17 \\
\hline 20 & Assy Station & $\begin{array}{l}\text { Connect inline connector CON22 (Type: plug Shell size: 1 Number } \\
\text { of poles 2) to bulkhead Connector CON04 (Type: socket Shell size: } \\
\text { 1 Number of poles 2) located at position (2250,-500,325) and } \\
\text { Orientation (-0,-1,-0,4.37114e-08) }\end{array}$ & $\begin{array}{c}\text { Hand } \\
\text { Assembly }\end{array}$ & 6.75 \\
\hline 30 & Assy Station & $\begin{array}{l}\text { Connect inline connector CON23 (Type: plug Shell size: 2 Number } \\
\text { of poles 7) to bulkhead connector CON05 (Type: socket Shell size: } \\
\text { 2 Number of poles 7) located at position (1750,-500,325) and } \\
\text { Orientation (-0,-1,-0,4.37114e-08) }\end{array}$ & $\begin{array}{c}\text { Hand } \\
\text { Assembly }\end{array}$ & 4.58 \\
\hline 40 & Assy Station & $\begin{array}{l}\text { Connect inline connector CON24 (Type: socket Shell size: 2 } \\
\text { Number of poles 7) to bulkhead connector CON10 (Type: plug } \\
\text { Shell size: 2 Number of poles 7) located at position } \\
(-2250,-500,-2175) \text { and Orientation (-0,-1,-0,4.37114e-08) }\end{array}$ & $\begin{array}{c}\text { Hand } \\
\text { Assembly }\end{array}$ & 7.69 \\
\hline
\end{tabular}

STANDARD ASSEMBLY TIMES FOR EACH COMPONENT

$\begin{array}{llll}\text { Component } & \text { Assembly Time }(\mathrm{s}) & \text { Component } & \text { Assembly Time (s) } \\ \text { CAB02 } & 10.30 & \text { CON22 } & 22.44 \\ \text { CON23 } & 14.88 & \text { CON21 } & 21.42 \\ \text { CON24 } & 34.87 & \text { CON01 } & 7.170 \\ \text { CAB01 } & 15.70 & \text { CON04 } & 6.74 \\ \text { CON24 } & 34.87 & \text { CON05 } & 4.58\end{array}$

Figure 9: Assembly Plans for Building Cable Harness and Installing Cable Harness

These outputs show conclusively that real world plans can be generated automatically from user interaction with immersive VR design and planning systems.

CONCLUSIONS - This research has shown that it is possible using HMD immersive VR to successfully both design and subsequently plan the assembly and installation of cable harnesses. It is possible to examine, categorise and measure in detail the wide range of design 
activities carried out by cable harness design engineers. These novel categorisations, along with their subsequent analyses, have provided a much more detailed understanding of design methods in this domain. Areas for interface improvement have been identified, e.g. more effective navigation tools, more effective menus and the benefits of 3D spatial design and interaction. As a consequence of this, this research is being extended to apply this categorisation scheme within cable harness CAD design environments for direct comparison with VR functionality as well as being used for the acquisition and formalisation of design ontologies related to cable harness design strategies and solutions. Cable harness assembly planning and installation planning are also feasible with real-world times being mapped onto virtual equivalent operations.

\section{REFERENCES}

1. Jayaram S, Vance J, Gadh R, Jayaram U, Srinivasan H, Assessment of VR Technology and its Application to Engineering Problems, Computing and Information Science in Engineering, Volume 1, pp72-83, 2001.

2. UK Health and Safety Executive, HSE Contract Research Report 274/2000, 2000.

3. Howarth PA, The Multi-Factorial Causes of Virtual Simulation Sickness, VISERG, Loughborough University, UK, 1997.

4. Howarth PA, Oculomotor changes within virtual environments, Applied Ergonomics Volume 30, pp59-67, 1999.

5. Howarth PA, Costello PJ, The Nauseogenicity of Using a Head-Mounted Display, Configured as a Personal Viewing System for an Hour, FIVE '96; Pisa, Italy, 1996.

6. Howarth PA, Costello PJ, The Occurrence of Virtual Simulation Sickness Symptoms when an HMD was used as a Personal Viewing System, Displays, Volume 18, pp107-116, 1997.

7. Gomes de Sa G, Zachmann G, Virtual Reality as a Tool for Verification of Assembly and Maintenance Processes, Computers and Graphics Journal, Volume 23, pp389-403, 1999.

8. Ng FM, Ritchie JM, Simmons JEL, Dewar RG, Designing Cable Harness Assemblies in Virtual Environments, Materials Processing Technology, Volume 107, pp37-43, 2000.

9. Cruz-Neira C, Sandin DJ, DeFanti TA, Kenyon RV, Hart JC, The CAVE: Audio Visual Experience Automatic Virtual Environment, Communications of the ACM, Volume 35, Part 6, pp65-72, 1992.

10. Weyrich M, Drews P, An Interactive Environment for Virtual Manufacturing: the Virtual Workbench, Computers in Industry, Volume 38, pp5-15, 1999.

11. Dani TH, Gadh R, Creation of Concept Shape Design via a Virtual Reality Interface, Computer Aided Design, Volume 29, Part 8, pp555-563, 1997.

12. Varga E, Horvath I, Rusak Z, de Smit B, Broek H, Survey and Investigation of Hand Motion Processing Technologies for Compliance with Shape Conceptualisation, Proceedings of DETC'04 ASME Design Engineering Technical Conferences and Computers and Information in Engineering Conference; ASME, DETC2004/CIE-57710, pp 1-14, 2004.

13. Ng FM, Virtual Reality and Computer-Based Tools for the Routing of Cable Harnesses, PhD Thesis, Heriot-Watt University, Edinburgh, 1999.

14. Conru AB. Computational Support for Interactive Cable Harness Routing and Design, 19th Annual ASME Design Automation Conference, pp 551-558, 1993.

15. Conru AB, A Genetic Approach to the Cable Harness Routing Problem, IEEE Conference on Evolutionary Computation, pp 200-205, 1994. 
16. Wolter J, Kroll E, Towards Assembly Sequence Planning with Flexible Parts, IEEE International Conference on Robotics and Automation, IEEE, pp 1517-1524, 1996.

17. Zhu D, Latombe JC, Pipe Routing = Path Planning (with many constraints), IEEE International Conference on Robotics and Automation, pp 1940-1947, 1991.

18. Holt POB, Ritchie JM, Day PN, et al, Immersive Virtual Reality in Manufacturing: Design Metaphors and Cognitive Ergonomics, Computing and Information Science in Engineering, Volume 4, Part 3, pp161-170, 2004.

19. Fischer AG, Chipperfield KC, Vance JM, VR Hose: Hydraulic Hose Routing in Virtual Reality with Jack ${ }^{\mathrm{TM}}$, AIAA/ISSMO Symposium on Multidisciplinary Analysis and Optimization, Atlanta, 2002.

20. Caudell TP, Mizell, DW, Augmented Reality: An Application of Heads-up Display Technology to Manual Manufacturing Processes, IEEE Hawaii International Conference on System Sciences, 2, pp 659- 669, 1992.

21. Holt POB, Russell GT, Psychology as a Science of Design in Engineering, Proceedings of the British Psychological Society Volume 7, Part 2, pp115, 1999.

22. Simmons JEL, Ritchie JM, Holt POB, Russell GT, Human in the Loop: The Use of Immersive Virtual Reality to Aid Cable Harness Design, First CIRP(UK) Seminar on Digital Enterprise Technology, Durham, UK, pp 109-112, 1999.

23. Liang J, Green M, JDCAD: A Highly Interactive 3D Modeling System, Computers and Graphics (ACM), Volume 18, Part 4, pp499-506, 1994.

24. Gerber D, Bechmann D, Design and Valuation of the Ring Menu in Virtual Environments, Immersive Projection Technologies IPT 2004, Ames, Iowa, USA, 2004.

25. Ritchie JM, Dewar RD, Simmons JEL, The Generation and Practical Use of Plans for Manual Assembly using Immersive Virtual Reality, Engineering Manufacture, Institution of Mechanical Engineers, Part B, Volume 213, pp461-474, 1999. 